\title{
Vaccines against Drug Abuse: Morphine-Hapten Design and Synthesis ${ }^{+}$
}

\author{
István Köteles * and Sándor Hosztafi \\ Department of Pharmaceutical Chemistry, Semmelweis University, Hogyes Endre u. 9., H-1092 Budapest, \\ Hungary; hosztafi.sandor@pharma.semmelweis-univ.hu \\ * Correspondence: koteles.istvan@pharma.semmelweis-univ.hu \\ + Presented at the 23rd International Electronic Conference on Synthetic Organic Chemistry, \\ 15 November-15 December 2019. Available online: https:/ecsoc-23.sciforum.net/.
}

Published: 14 November 2019

\begin{abstract}
Drugs of abuse are small molecules that typically do not induce an antibody response following the administration. To induce antibodies against these kind of molecules, structural changes have to be made to obtain so called "haptens". The hapten must be coupled to immunogenic proteins, called "carriers". These connected derivatives are typically drug-linker adducts, in which the linker has a terminal functional group (i.e., carboxylic acid or aliphatic amine) that forms a covalent bond with the carrier. The efficacy of these conjugate vaccines depends on several factors including hapten design, coupling strategy, hapten density, carrier protein selection, and vaccine adjuvant. Six nor-normorphine compounds were reacted with ethyl acrylate and ethyl bromoacetate. After the synthesis of the specific esters we hydrolyzed them to receive the $\mathrm{N}$ carboxymethyl- and $\mathrm{N}$-carboxyethyl-normorphine derivatives. The next step was the coupling phase with glycine ethyl ester, but the reactions didn't work or the work-up process was not accomplishable. As an alternative route the normorphine-compounds were reacted with $\mathrm{N}$ chloroacetyl glycine ethyl ester. These products were hydrolyzed in alkaline media and after the work-up process all of the derivatives contained the free carboxylic group of the glycine sidechain. All of the glycine ester and the glycine carboxylic acid derivatives are under biological tests.
\end{abstract}

Keywords: hapten; vaccine; immunotherapy; $N$-demethylation; nor-compounds; morphine skeleton

\section{Introduction}

Drug abuse is a worldwide problem. Even today one of the most popular illegal substance is morphine and its derivative heroin beside cocaine and marihuana. These drugs have a very serious potent to cause damage not just to the individual but to the whole society as well [1,2].

To help the drug addicts-and now let's just focus on the opiate users-there isn't a lot of possibilities. The most common way is the methadone therapy. In this case the morphine or heroin is substituted with methadone because its half-life is longer then the illegal drugs. Therefore, the dosage of the morphine and heroin can be decreased until it reaches zero. After this it is possible to decrease the level of methadone as well without inducing the withdrawal effects of the opiates. Theoretically this protocol works fine but in practice it can be easily spoiled. Namely if the patient uses the illegal substance during the therapy all of the results that are achieved so far are just a waste of time, money and energy. Not even mention that the level of tolerance decreases as well and that can cause the death of the patient too.

For this problem an alternative solution can be the vaccination against these drugs [3]. Drugs of abuse are small molecules that typically do not induce an antibody response following the administration. To induce antibodies against these kind of molecules, structural changes have to be 
made to obtain so called "haptens". The hapten must be coupled to immunogenic proteins, called "carriers". These connected derivatives are typically drug-linker adducts, in which the linker has a terminal functional group (i.e., carboxylic acid or aliphatic amine) that forms a covalent bond with the carrier. The efficacy of these conjugate vaccines depends on several factors including hapten design, coupling strategy, hapten density, carrier protein selection, and vaccine adjuvant $[4,5]$.

\section{Materials and Methods}

To obtain a hapten molecule the morphine derivatives can be modified on different sites:

$\mathrm{C} 3-$ phenolic $\mathrm{OH}$

$\mathrm{C} 6-$ alcoholic $\mathrm{OH}$

$\mathrm{N}$-substitution of secondary nitrogen (nor-compounds)

For our purpose the desired normorphine derivatives (normorphine (1), dihydronormorphine (2), norcodeine (3), dihydronorcodein (4), noroxymorphone (5) and noroxycodone (6) (Figure 1)) could be obtained by the $\mathrm{N}$-demethylation of the starting molecules [6-12].

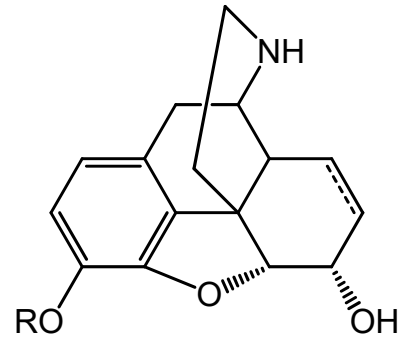

1: $\mathrm{R}=\mathrm{H} \quad \mathrm{C} 7=\mathrm{C} 8$

2: $\mathrm{R}=\mathrm{H} \quad \mathrm{C} 7-\mathrm{C} 8$

3: $\mathrm{R}=\mathrm{CH}_{3} \mathrm{C} 7=\mathrm{C} 8$

4: $\mathrm{R}=\mathrm{CH}_{3} \mathrm{C} 7-\mathrm{C} 8$

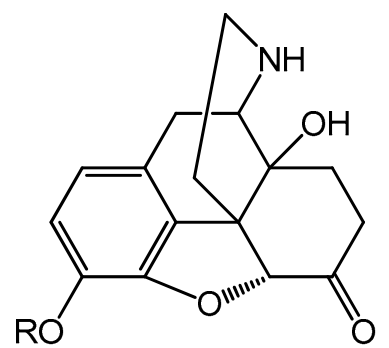

5: $\mathrm{R}=\mathrm{H}$

6: $\mathrm{R}=\mathrm{CH}_{3}$

Figure 1. Normorphine derivatives.

Codeine or dihydrocodeine can be $N$-demethylated with $\alpha$-chloro-ethyl chloroformate in 1,2dichloroethane solvent and the intermediate carbamate was heated with methanol to yield the hydrochloride salt of norcodeine (dihydronorcodeine) (Scheme 1).

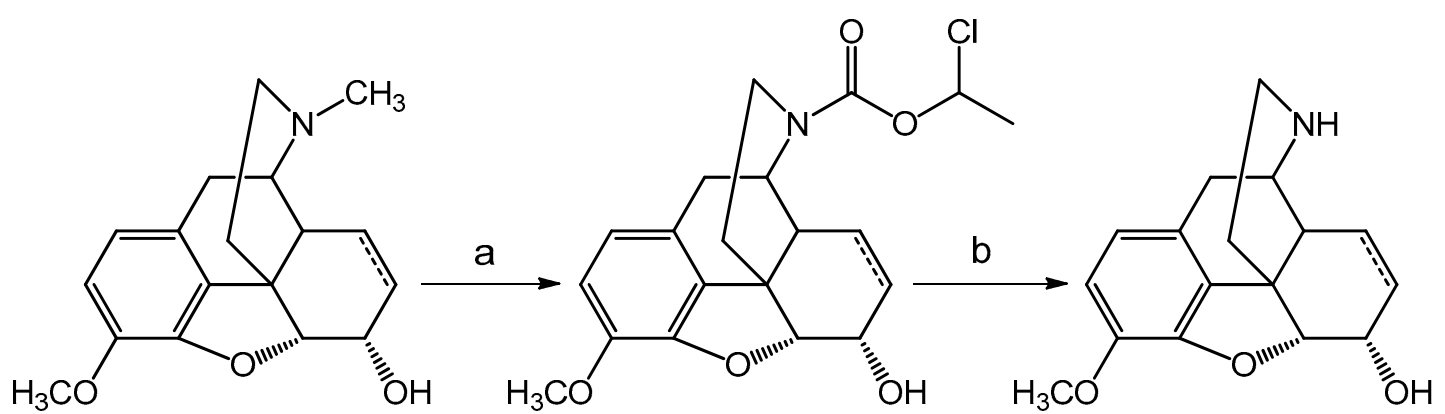

Scheme 1. N-demethylation of (dihydro)codeine: (a) $\alpha$-chloro-ethyl chloroformate, 1,2dichloroethane; (b) methanol, heating.

For the preparation of (dihydro)normorphine 3,6-diacetyl (dihydro)morphine was $\mathrm{N}$ demethylated with $\alpha$-chloro-ethyl chloroformate and after cleavage of the carbamate 3,6-diacetyl 
(dihydro)normorphine hydrochloride salt was obtained. Acid hydrolysis of 3,6-diacetyl (dihydro)normorphine yielded (dihydro)normorphine (Scheme 2).

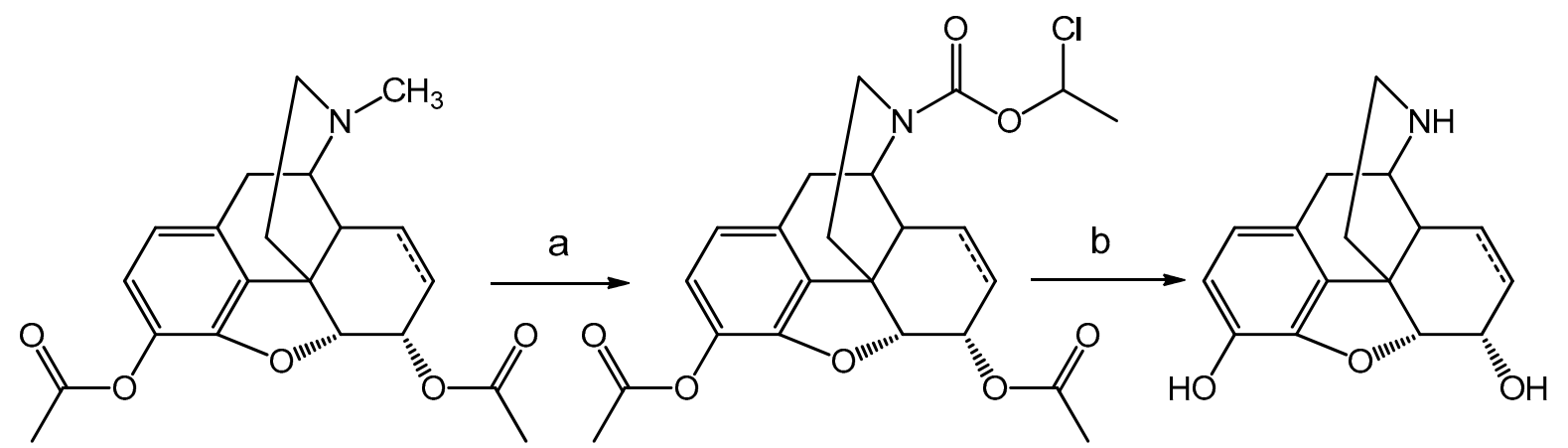

Scheme 2. N-demethylation of (dihydro)morphine: (a) $\alpha$-chloro-ethyl chloroformate, 1,2dichloroethane; (b) methanol, heating, acid hydrolysis.

3,14-di-O-acetyloxymorphone and 14-O-acetyloxycodone were $\mathrm{N}$-demethylated by the above procedure, and these reactions resulted in 3,14-di-O-acetyloxynormorphone hydrochloride and 14$\mathrm{O}$-acetylnoroxycodone hydrochloride. Acid hydrolysis $(10 \% \mathrm{HCl}, 6 \mathrm{~h}$ reflux $)$ yielded noroxymorphone and noroxycodone (Scheme 3).
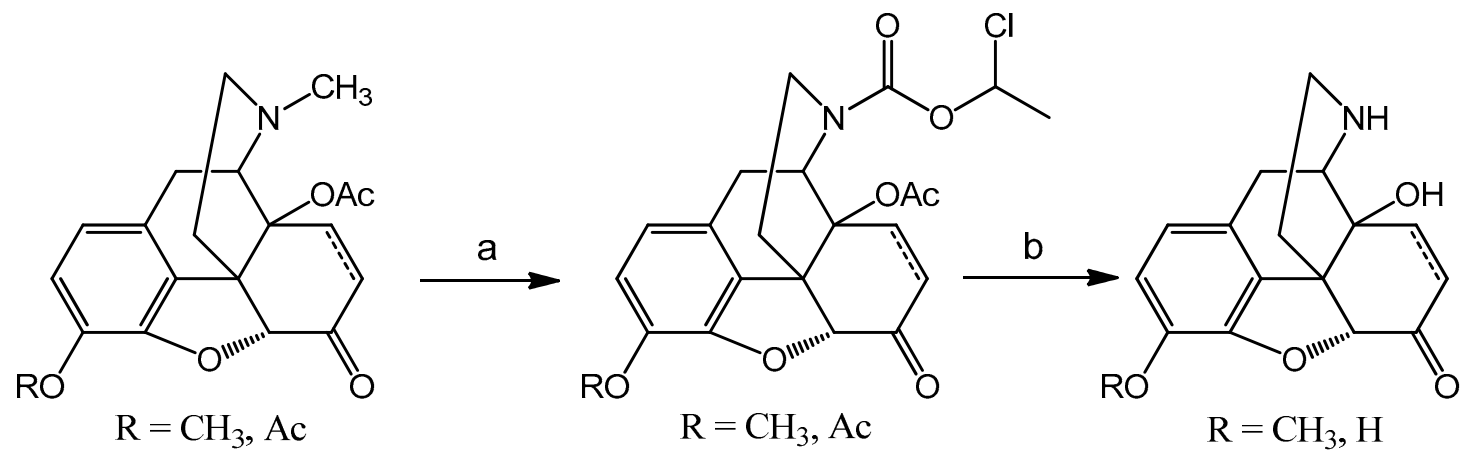

Scheme 3. $N$-demethylation of oxymorphone and oxycodone: (a) $\alpha$-chloro-ethyl chloroformate, 1,2dichloroethane; (b) methanol, heating, acid hydrolysis.

The next step is the $\mathrm{N}$-alkylation of the norcompounds. Depending on the linker chain size different methods were used.

In the case of methylene bridge ethyl bromoacetate was used (Scheme 4). Depending on the solubility the starting nor-compound was dissolved in dimethyl formamide (DMF) or acetonitrile $(\mathrm{ACN})$. In the presence of sodium bicarbonate, the reaction mixture was refluxed for $16 \mathrm{~h}$. The conversion of the reaction was monitored by thin layer chromatography (TLC). The inorganic salts were filtered and in the case of acetonitrile it was evaporated in vacuo. The DMF was vacuum distillated and water was added to the residue. The aqueous phase was basified with cc. ammonia and was extracted with chloroform. The organic phase was dried over sodium sulfate. The solution was filtered and the chloroform was evaporated to obtain the specific $\mathrm{N}$-carboxymethyl-norcompound ethyl ester. 


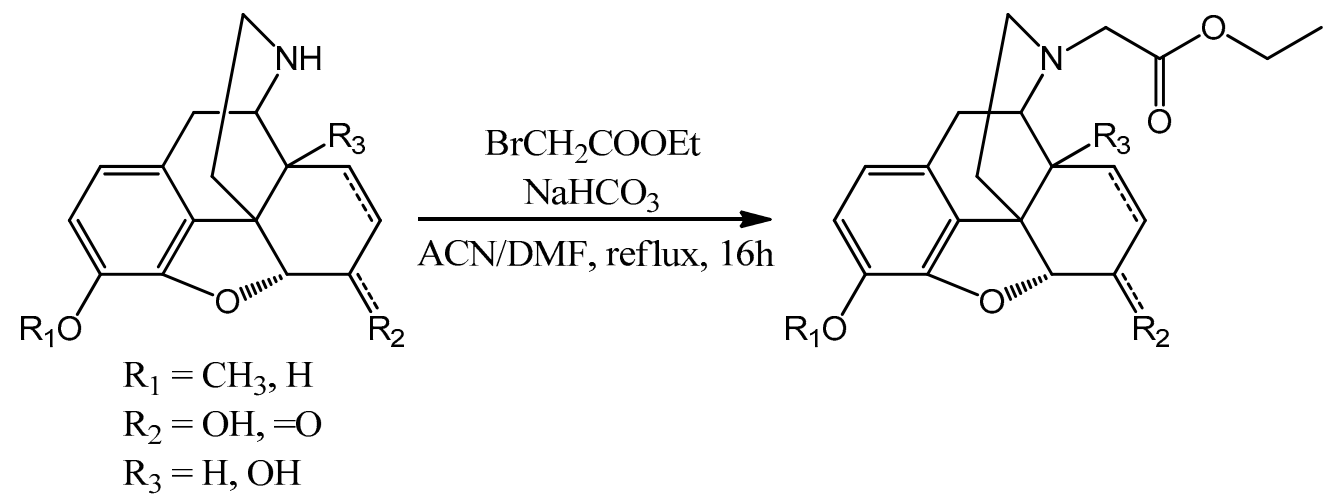

Scheme 4. $\mathrm{N}$-alkylation of nor-compounds: ethyl bromoacetate, sodium bicarbonate, acetonitrile or dimethyl formamide, refl. $16 \mathrm{~h}$.

For the ethylene linker ethyl acrylate was utilized (Scheme 5). The nor-molecule was dissolved in ethanol and in the presence of triethylamine the mixture was refluxed for $3 \mathrm{~h}$. After checking the TLC, the reaction mixture was evaporated in vacuo. The product was in every case the $\mathrm{N}$ carboxyethyl-nor-compound ethyl ester.

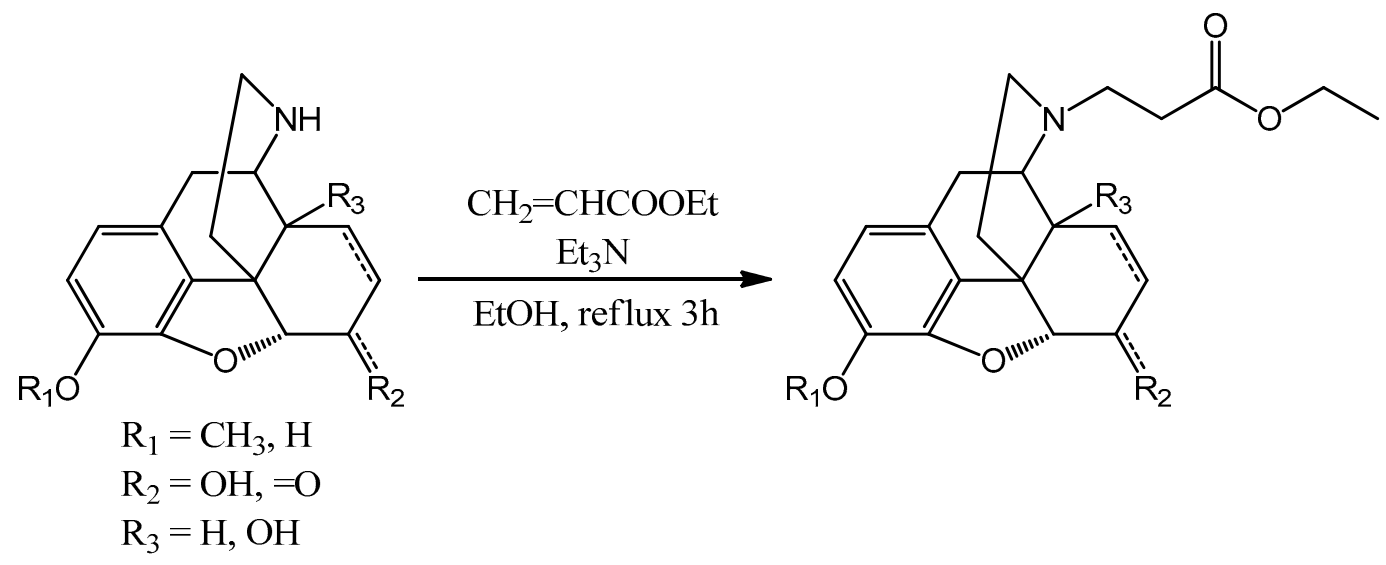

Scheme 5. $\mathrm{N}$-alkylation of nor-compounds: ethyl acrylate, triethyl amine, ethanol, refl. $3 \mathrm{~h}$.

After obtaining of the aforementioned esters all of them were hydrolyzed (Scheme 6). Sodium hydroxide was used in every case, the reaction mixture was heated up to $60^{\circ} \mathrm{C}$ and was stirred for 30-60 min. TLC was used to monitor the reaction. After the conversion the $\mathrm{pH}$ was set to 3-4 and the mixture was evaporated to dryness to get the hydrochloride salt.

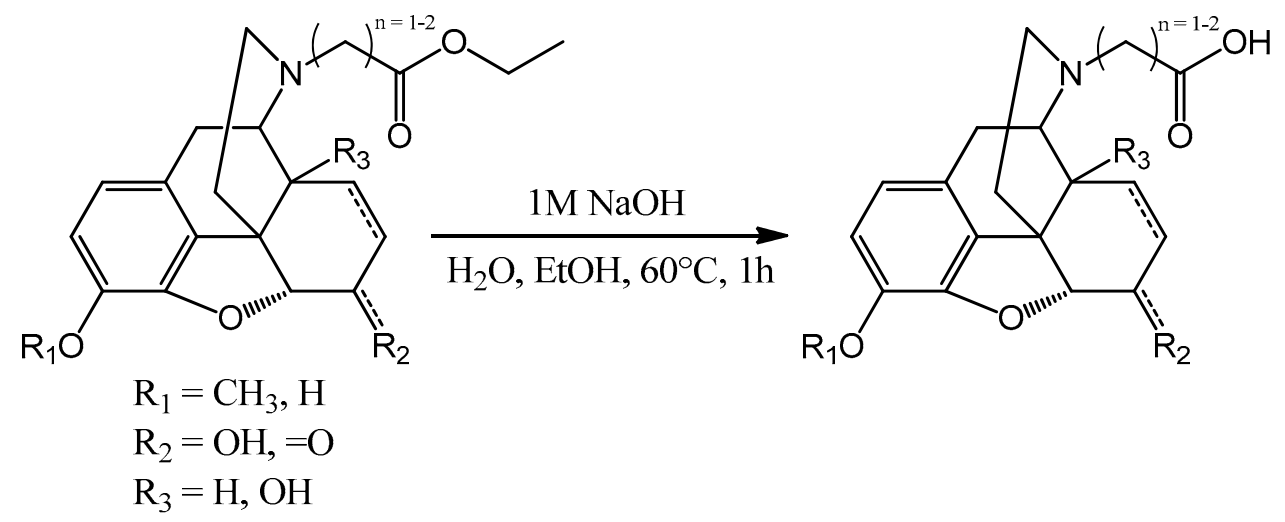

Scheme 6. Hydrolysis of esters: $1 \mathrm{M} \mathrm{NaOH}$, ethanol, water, heating, $1 \mathrm{~h}$. 
In the next step the carboxylic group containing molecules were supposed to react with glycine ethyl ester (Scheme 7). Reagents that are common in peptide syntheses were used like $N, N^{\prime}$ dicyclohexyl carbodiimide (DCCI) or 1-ethyl-3-(3-dimethylaminopropyl)-carbodiimide (EDAC) and 1-hydroxybenzotriazole ( $\mathrm{HOBt})$. Unfortunately, these connections were very low yielding reactions and the mixtures did not result the desired compounds. To obtain the glycine derivatives an alternative route has been chosen.
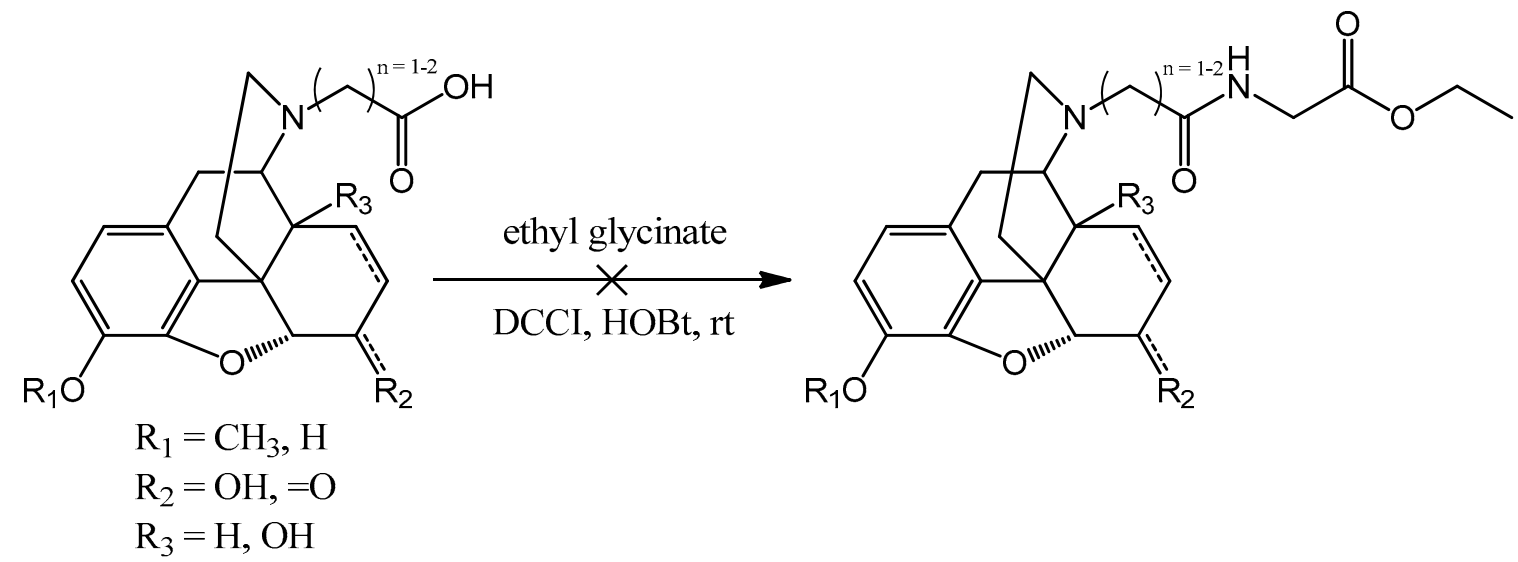

Scheme 7. Failed amino acid coupling: glycine ethyl ester, DCCI or EDAC, HOBt, water, room temperature.

In the case of methylene bridge containing compounds the retro-synthetic analysis revealed that the linker between the nor-compounds and the glycine ethyl ester could be the chloroacetyl chloride. Because of this $\mathrm{N}$-chloroacetly-glycine ethyl ester was a good choice as the reagent (Scheme 8).

The nor-compound was dissolved in acetonitrile. In the presence of potassium iodide and sodium bicarbonate it was reacted with $\mathrm{N}$-chloroacetly-glycine ethyl ester. The mixture was heated and stirred until the conversion was complete. After the evaporation water and concentrated ammonia was added to the residue and it was extracted with chloroform. The organic phase was dried on sodium sulfate and after the evaporation of the organic solvent the desired product was obtained. Column chromatography was used if purification was needed.

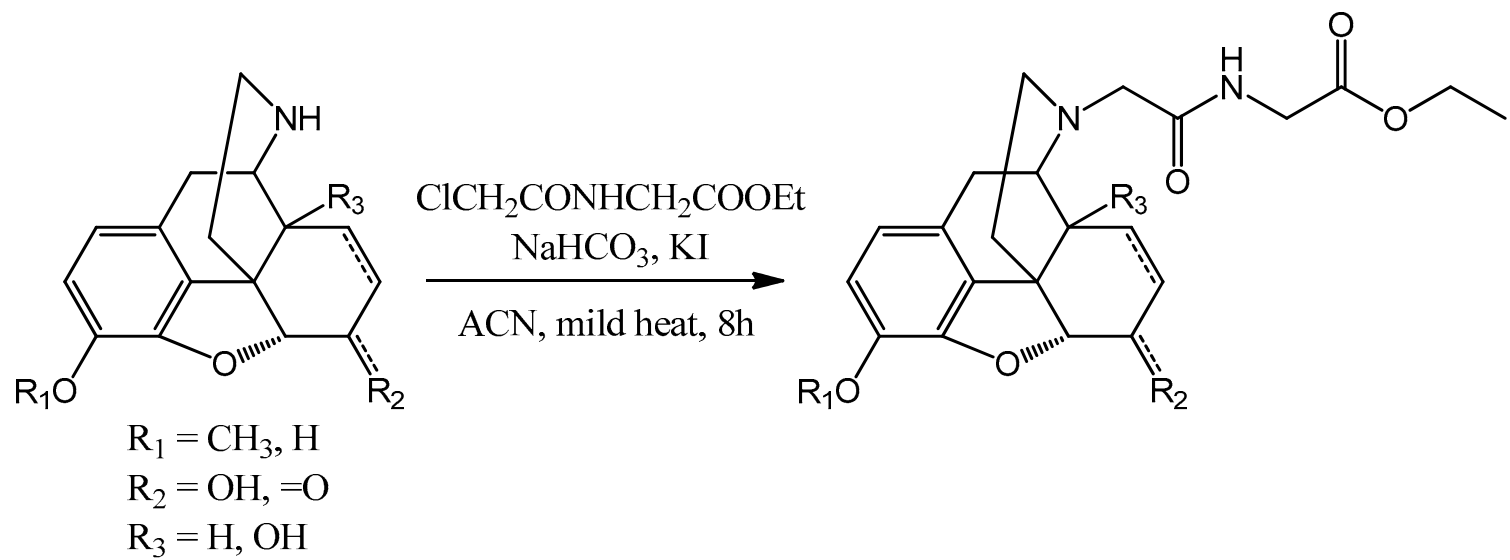

Scheme 8. Amino acid connected hapten: $N$-chloroacetly-glycine ethyl ester, sodium bicarbonate, potassium iodide, acetonitrile, mild heating, $8 \mathrm{~h}$.

The esters from the previous reaction were hydrolyzed as mentioned above after reacting with ethyl bromoacetate and ethyl acrylate. 


\section{Results}

Totally 36 compounds have been synthetized and 32 of them are brand new molecules $(N$ carboxymethyl-normorphine ethyl ester, $N$-carboxyethyl-normorphine ethyl ester, $N$-carboxyethylnormorphine, $N$-carboxyethyl-norcodein were previously synthesized) [13,14]. All of them are under physico-chemical examination and 8 of them ( $N$-acetylglycine-normorphine ethyl ester, $N$ acetylglycine-dihydronormorphine ethyl ester, $N$-acetylglycine-noroxymorphone ethyl ester, $N$ acetylglycine-noroxycodone ethyl ester, $N$-acetylglycine-normorphine, $N$-acetylglycinedihydronormorphine, $N$-acetylglycine-noroxymorphone, $N$-acetylglycine-noroxycodone) are sent for biological and animal experiments.

\subsection{N-demethylation Reactions}

Codeine or dihydrocodeine $(3 \mathrm{mmol})$ was dissolved in dried 1,2-dichloroethane $(30 \mathrm{~mL})$ then sodium hydrogen carbonate $(0.84 \mathrm{~g})$ was added to the solution. To this ice-cold mixture $\alpha$-chloroethyl chloroformate $(10 \mathrm{mmol})$ was added dropwise and the reaction mixture was stirred at room temperature for $30 \mathrm{~min}$. then heated at $90^{\circ} \mathrm{C}$ overnight. The resulting suspension was cooled to room temperature and inorganic salts were filtered off. The filtrate was evaporated under reduced pressure and the residue was dissolved in methanol and the solution was heated at $60{ }^{\circ} \mathrm{C}$ for $6 \mathrm{~h}$. Methanol was removed under reduced pressure to yield a crystalline solid, the hydrochloride salt of norcodeine or dihydronorcodeine. Free base was liberated with $10 \%$ sodium hydroxide $(\mathrm{pH}=9)$ and was extracted with chloroform. The chloroform extract was dried (sodium sulfate) and evaporated to result in the norcompound.

Norcodeine yield: $87 \%$, m.p.: $185^{\circ} \mathrm{C}$ (acetone)

Dihydronorcodeine yield: $83 \%$ m.p.: $194^{\circ} \mathrm{C}$ (ethanol)

(Dihydro)normorphine was prepared by $N$-demethylation of diacetyl (dihydro)morphine by means of $\alpha$-chloroethyl chloroformate using the above-mentioned procedure and the carbamate was treated with methanol at $60{ }^{\circ} \mathrm{C}$ to afford diacetyl (dihydro)normorphine hydrochloride salt. (Dihydro)normorphine was obtained by hydrolysis of diacetyl (dihydro)normorphine $\mathrm{x} \mathrm{HCl}$ in $5 \%$ $\mathrm{HCl}$ at $100{ }^{\circ} \mathrm{C}$ for $4 \mathrm{~h}$. (Dihydro)normorphine base was precipitated with $25 \%$ ammonia solution ( $\mathrm{pH}$ =9-10) and filtered off.

Normorphine yield: $84 \%$ m.p.: $273-275^{\circ} \mathrm{C}$.

Dihydronormorphine yield: $80 \%$

14-O-Acetyloxycodone $(2 \mathrm{mmol})$ was $\mathrm{N}$-demethylated with $\alpha$-chloroethyl chloroformate (10 $\mathrm{mmol}$ ) for $16 \mathrm{~h}$. The reaction was monitored by thin-layer chromatography to check the conversion, if it was necessary another $5 \mathrm{mmol}$ portion of $\alpha$-chloroethyl chloroformate was added. The carbamate intermediate was decomposed in methanol to yield the hydrochloride salt of 14-Oacetylnoroxycodone. Acid hydrolysis in refluxing $10 \% \mathrm{HCl}$ for $6 \mathrm{~h}$ resulted in the hydrochloride salt of noroxycodone. The free base of noroxycodone was liberated from the acid solution $10 \%$ sodium hydroxide $(\mathrm{pH}=10)$ and it was extracted with chloroform. The chloroform extract was dried under sodium sulfate and after evaporation of the solution afforded the oily noroxycodone, which was rubbed with diethyl ether to produce crystalline material.

Noroxycodone yield: 86\% m.p.: 163-166 C.

$\mathrm{N}$-demethylation of 3,14-di-O-acetyloxymorphone yielded the hydrochloride salt of 3,14-di-Oacetylnoroxymorphone, which was hydrolyzed in $10 \% \mathrm{HCl}$ solution. Noroxymorphone base was precipitated from the acid solution with $25 \%$ ammonia solution to yield noroxymorphone which is pure for further reactions.

Noroxymorphone yield: $81 \%$ m.p.: $>280^{\circ} \mathrm{C}$. 


\subsection{General Synthesis of N-carboxymethyl-nor-compound Ethyl Esters}

The specific normorphine derivative $(2 \mathrm{mmol})$ was dissolved in $30 \mathrm{~mL}$ of acetonitrile. In the presence of sodium bicarbonate $(10 \mathrm{mmol})$ ethyl bromoacetate $(2.4 \mathrm{mmol})$ was added to the solution. The mixture was stirred and refluxed for $16 \mathrm{~h}$. After the TLC showed no more starting compound the inorganic salts were filtered and the solvent was evaporated. Water $(30 \mathrm{~mL})$ was added to the residue and the $\mathrm{pH}$ was set around 9 with conc. ammonia. Then it was extracted with chloroform $(3 \times 25 \mathrm{~mL})$ and after unifying the organic phases it was dried on sodium sulfate. After filtration the chloroform was evaporated. If it was necessary column chromatography was used. (Choloroform: Methanol 9:1)

$N$-carboxymethyl-normorphine ethyl ester yield: $86 \%$

$N$-carboxymethyl-dihydronormorphine ethyl ester yield: $84 \%$

$N$-carboxymethyl-norcodeine ethyl ester yield: $90 \%$

$N$-carboxymethyl-dihydronorcodeine ethyl ester yield: $88 \%$

$N$-carboxymethyl-noroxymorphone ethyl ester yield: $82 \%$

$\mathrm{N}$-carboxymethyl-noroxycodone ethyl ester yield: $87 \%$

\subsection{General Synthesis of N-carboxymethyl-nor-compounds}

The specific $N$-carboxymethyl-nor-compound ethyl ester $(0.5 \mathrm{mmol})$ was added to the mixture of ethanol $(1 \mathrm{~g})$ and water $(2.5 \mathrm{~mL})$. The mixture was reacted with sodium hydroxide $(1 \mathrm{M}, 0.5 \mathrm{mmol})$ for $1 \mathrm{~h}$ at $60^{\circ} \mathrm{C}$. After the reaction the $\mathrm{pH}$ was set to $3-4$ with $10 \% \mathrm{HCl}$ solution. Then the solvent was evaporated to obtain the hydrochloride salt of the desired compound.

$\mathrm{N}$-carboxymethyl-normorphine yield: $92 \%$

$\mathrm{N}$-carboxymethyl-dihydronormorphine yield: $93 \%$

$\mathrm{N}$-carboxymethyl-norcodeine yield: $95 \%$

$\mathrm{N}$-carboxymethyl-dihydronorcodeine yield: $90 \%$

$\mathrm{N}$-carboxymethyl-noroxymorphone yield: $96 \%$

$\mathrm{N}$-carboxymethyl-noroxycodone yield: $94 \%$

\subsection{General Synthesis of N-carboxyethyl-nor-compound Ethyl Esters}

The specific normorphine derivative $(2 \mathrm{mmol})$ was dissolved in $30 \mathrm{~mL}$ of ethanol. In the presence of triethylamine $(1 \mathrm{~mL})$ ethyl acrylate $(2.4 \mathrm{mmol})$ was added to the solution. The mixture was stirred and refluxed for $3 \mathrm{~h}$. After the TLC showed no more starting compound the solvent was evaporated. If it was necessary column chromatography was used. (Choloroform: Metahnol 9:1)

$N$-carboxyethyl-normorphine ethyl ester yield: $98 \%$

$\mathrm{N}$-carboxyethyl-dihydronormorphine ethyl ester yield: $96 \%$

$\mathrm{N}$-carboxyethyl-norcodeine ethyl ester yield: $97 \%$

$\mathrm{N}$-carboxyethyl-dihydronorcodeine ethyl ester yield: $93 \%$

$\mathrm{N}$-carboxyethyl-noroxymorphone ethyl ester yield: $99 \%$

$\mathrm{N}$-carboxyethyl-noroxycodone ethyl ester yield: $98 \%$

\subsection{General Synthesis of N-carboxyethyl-nor-compounds}

The specific $N$-carboxyethyl-nor-compound ethyl ester $(0.5 \mathrm{mmol})$ was added to the mixture of ethanol $(1 \mathrm{~g})$ and water $(2.5 \mathrm{~mL})$. The mixture was reacted with sodium hydroxide $(1 \mathrm{M}, 0.5 \mathrm{mmol})$ for $1 \mathrm{~h}$ at $60^{\circ} \mathrm{C}$. After the reaction the $\mathrm{pH}$ was set to $3-4$ with $10 \% \mathrm{HCl}$ solution. Then the solvent was evaporated to obtain the hydrochloride salt of the desired compound.

$\mathrm{N}$-carboxyethyl-normorphine yield: $96 \%$

$\mathrm{N}$-carboxyethyl-dihydronormorphine yield: $96 \%$

$\mathrm{N}$-carboxyethyl-norcodeine yield: $93 \%$

$\mathrm{N}$-carboxyethyl-dihydronorcodeine yield: $95 \%$

$\mathrm{N}$-carboxyethyl-noroxymorphone yield: $99 \%$ 
N-carboxyethyl-noroxycodone yield: $96 \%$

\subsection{General Synthesis of N-acetyl-glycine-nor-compound Ethyl Esters}

The specific normorphine derivative $(2 \mathrm{mmol})$ was dissolved in $30 \mathrm{~mL}$ of acetonitrile. In the presence of sodium bicarbonate $(10 \mathrm{mmol})$ and potassium iodide $(2.4 \mathrm{mmol}) \mathrm{N}$-chloroacetyl-glycine ethyl ester $(2.4 \mathrm{mmol})$ was added to the solution. The mixture was stirred and refluxed for $8 \mathrm{~h}$. After the TLC showed no more starting compound the inorganic salts were filtered and the solvent was evaporated. If it was necessary column chromatography was used. (Choloroform: Methanol 9:1)

$\mathrm{N}$-acetyl-glycine-normorphine ethyl ester yield: $94 \%$

$\mathrm{N}$-acetyl-glycine-dihydronormorphine ethyl ester yield: $91 \%$

$\mathrm{N}$-acetyl-glycine -norcodeine ethyl ester yield: $90 \%$

$\mathrm{N}$-acetyl-glycine -dihydronorcodeine ethyl ester yield: $89 \%$

$\mathrm{N}$-acetyl-glycine -noroxymorphone ethyl ester yield: $95 \%$

$\mathrm{N}$-acetyl-glycine -noroxycodone ethyl ester yield: $96 \%$

\subsection{General Synthesis of N-acetyl-glycine-nor-compounds}

The specific $N$-acetyl-glycine-nor-compound ethyl ester $(0.5 \mathrm{mmol})$ was added to the mixture of ethanol $(1 \mathrm{~g})$ and water $(2.5 \mathrm{~mL})$. The mixture was reacted with sodium hydroxide $(1 \mathrm{M}, 0.5 \mathrm{mmol})$ for $1 \mathrm{~h}$ at $60^{\circ} \mathrm{C}$. After the reaction the $\mathrm{pH}$ was set to $3-4$ with $10 \% \mathrm{HCl}$ solution. Then the solvent was evaporated to obtain the hydrochloride salt of the desired compound.

$\mathrm{N}$-acetyl-glycine-normorphine yield: $98 \%$

$\mathrm{N}$-acetyl-glycine-dihydronormorphine yield: $94 \%$

$\mathrm{N}$-acetyl-glycine-norcodeine yield: $99 \%$

$\mathrm{N}$-acetyl-glycine-dihydronorcodeine yield: $95 \%$

$\mathrm{N}$-acetyl-glycine-noroxymorphone yield: $98 \%$

$\mathrm{N}$-acetyl-glycine-noroxycodone yield: $93 \%$

\section{Discussion}

12 hapten type molecules were synthetized from another 12 ethyl ester precursors. To model the peptide connection 6 glycine ethyl ester derivatives were obtained and all 6 have been hydrolyzed as well to achieve the free acidic forms. 8 of the $12 \mathrm{~N}$-acetyl-glycine-nor-compounds are under biological studies, while the other molecules are under physico-chemical measurements. The structures of all of these molecules are confirmed by NMR spectroscopy.

\section{Conclusions}

We have successfully developed different reaction ways to obtain 36 hapten-like normorphine derivatives and 32 of them are synthetized for the very first time. The most potent compounds are under biological experiments. Right now we are working on new sidechains to change the linker and the amino acid part as well.

Supplementary Materials: The following are available online at http://www.mdpi.com/2504-3900/41/1/48/s1.

Funding: This research received no external funding.

Conflicts of Interest: The authors declare no conflict of interest.

\section{References}

1. UNODC, World Drug Report 2018. Available online: https://www.unodc.org/wdr2018/ (accessed on 9 November 2019).

2. Olson, M.E.; Eubanks, L.M.; Janda, K.D. Chemical Intervent ions for the Opioid Crisis: Key Advances and Ramaining Challenges. J. Am. Chem. Soc. 2019, 141, 5, 1798-1806.

3. Kinsey, B. Vaccines against drugs of abuse: Where are we now? Ther. Adv. Vaccines 2014, 2, 106-117. 
4. Torres, O.; Alving, C.; Jacobson, A.; Rice, K.; Matyas, G. Practical Considerations for the Development of Vaccines Against Drugs of Abuse. In Biologics to Treat Substance Use Disorders: Vaccines, Monoclonal Antibodies, and Enzymes, 1st ed.; Montoya, I.D., Ed.; Springer International Publishing: Cham, Switzerland, 2016; pp. 397-424.

5. Bremer, P.t.; Schlosburg, J.E.; Banks, M.L.; Steele, F.F.; Zhou, B.; Poklis, J.L.; Janda, K.D. Development of a Clinically Viable Heroin Vaccine. J. Am. Chem. Soc. 2017, 139, 8601-8611.

6. Olofson, R.A.; Martz, J.T.; Senet, J.P.; Piteau, M.; Malfroot, T. A new reagent for the selective high yield Ndealkylation of tertiary amines: Improved synthesis of naltrexone and nalbuphine. J. Org. Chem. 1984, 49, 2081-2082.

7. Ninan, A.; Sainsbury, M. An improved synthesis of noroxymorphone. Tetrahedron 1992, 48, 6709-6716.

8. Olofson, R.A.; Schnur, R.C.; Bunes, L.A. N-Dealkylation of Tertiary Amines. U.S. Patent 3905981,16 September 1975.

9. Olofson, R.A.; Pepe, J.P. N-dealkylation of N-alkyl-14-hydroxymorphinans and Derivatives Thereof. U.S. Patent 4141 897, 27 February 1979.

10. Olofson, R.A.; Pepe, J.P. N-alkyl-14-hydroxymorphinans and Derivatives. U.S. Patent 4161 597, 17 July 1979.

11. Blumberg, H.; Pachter, I.J.; Matossian, Z. 14-Hydroxydihydronormorphinone derivatives. U.S. Patent 3332 950, 25 July 1967.

12. Thavaneswaran, S.; McCamley, K.; Scammells, P.J. N-Demethylation of Alkaloids. Nat. Prod. Comm. 2006, 1, 885-897.

13. Clark, R.L.; Pessolano, A.A.; Weijlard, J.; Pfister, K. N-Substituted Epoxymorphinans. J. Am. Chem. Soc. 1953, $75,4963-4966$.

14. Wieczorek, U.; Nagakura, N.; Sund, C.; Jendrzejewski, S.; Zenk, M.H. Radioimmunoassay determination of six opium alkaloids and its application to plant screening. Phytochemistry 1986, 25, 2639-2646.

(C) 2019 by the authors. Licensee MDPI, Basel, Switzerland. This article is an open access article distributed under the terms and conditions of the Creative Commons Attribution (CC BY) license (http://creativecommons.org/licenses/by/4.0/). 